\title{
Case report: coeliac disease as a cause of secondary failure of glibenclamide therapy in a patient with permanent neonatal diabetes due to $K C N J 11 /$ R201C mutation
}

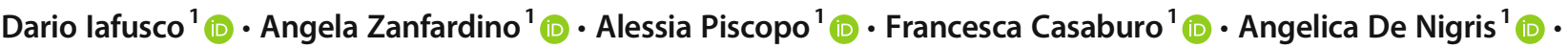 \\ Salvatore Alfiero ${ }^{1}$ (D) $\cdot$ Giuseppina Russo $^{1}$ (D) $\cdot$ Mattia Arenella $^{1}$ (D) Maria Cecilia Russo $^{1}$ (D) Fabrizio Barbetti $^{2}$ (i)
}

Received: 19 November 2020 / Accepted: 8 January 2021 / Published online: 14 May 2021

(C) The Author(s) 2021

Keywords Coeliac disease $\cdot$ Glibenclamide therapy $\cdot$ KCNJ11 mutation $\cdot$ Permanent neonatal diabetes $\cdot$ Secondary failure

\begin{tabular}{ll}
\multicolumn{2}{l}{ Abbreviations } \\
DKA & Diabetic ketoacidosis \\
IAA & Insulin autoantibodies \\
IA2 & Islet antigen 2 \\
$\mathrm{~K}_{\text {ATP }}$ & ATP-regulated $\mathrm{K}^{+}$(channel) \\
NDM & Neonatal diabetes mellitus \\
PNDM & Permanent NDM \\
SGA & Small for gestational age \\
TG2 & Transglutaminase 2 \\
ZnT8 & Zinc transporter 8
\end{tabular}

To the Editor: Activating mutations in the ATP-regulated $\mathrm{K}^{+}\left(\mathrm{K}_{\mathrm{ATP}}\right)$ channel genes $K C N J 11$ and $A B C C 8$ cause neonatal diabetes mellitus (NDM); patients with these mutations may respond to oral sulfonylureas [1,2]. Recently, we have shown that sulfonylurea therapy in 83 patients with permanent NDM (PNDM) associated with KCNJ11 mutations maintained its full efficacy in 75 patients (93\%) over a period of 10 years, while six needed some additional insulin [3]. To date, while non-responders have been described [4] no severe secondary failure has been reported.

Dario Iafusco

dario.iafusco@unicampania.it

1 Department of Pediatrics, University of Campania 'Luigi Vanvitelli', Naples, Italy

2 Department of Experimental Medicine, University of Rome Tor Vergata, Rome, Italy

\section{Methods: clinical case}

An infant born small for gestational age (SGA; $2100 \mathrm{~g}$, $<3$ rd centile), the daughter of a PNDM patient carrying the KCNJ11 mutation R201C, was diagnosed with neonatal diabetes right after birth (blood glucose fluctuating between 4.4 and $22.2 \mathrm{mmol} / \mathrm{l}(80$ and $400 \mathrm{mg} / \mathrm{dl})$. The markers of autoimmune diabetes (autoantibodies to GAD, islet antigen 2 [IA2] and zinc transporter 8 [ZnT8] and insulin autoantibodies [IAA]) were negative. Family history prompted us to commence treatment with the sulfonylurea glibenclamide at a dose of $0.36 \mathrm{mg} \mathrm{kg}^{-1} \mathrm{day}^{-1}$ (in three administrations) on day 3 of life, before the report confirming that she had inherited the paternal mutation (obtained at 12 days of life). However, because of a failure to thrive (steadily decreasing body weight, down to $1950 \mathrm{~g}$ ) and unsatisfactory metabolic control, insulin was added to sulfonylureas for about a month, resulting in the patient's weight gain of approximately $180 \mathrm{~g}$ per week. At 42 days of life she was finally weaned from insulin injections at the glibenclamide dose of $0.92 \mathrm{mg} \mathrm{kg}^{-1} \mathrm{day}^{-1}$. She remained in good metabolic control for 3 years, with $\mathrm{HbA}_{1 \mathrm{c}}$ (DCA-2000 Analyzer, Siemens Healtheeners, Germany) below $42 \mathrm{mmol} / \mathrm{mol}(6 \%)$ at every trimestral visit. At 38 months of age (June 2016), she presented with fever, vomiting and biochemical evidence of diabetic ketoacidosis (DKA): arterial $\mathrm{pH} 7.1$, blood glucose $22.2 \mathrm{mmol} / 1$ (400 mg/ dl), ketonaemia $6 \mathrm{mmol} / \mathrm{l}$, in the presence of a relative decrease of body weight that occurred a few months before the onset of hyperglycaemia. $\mathrm{HbA}_{1 \mathrm{c}} 6$ months before and at the time of the DKA episode was normal $(37 \mathrm{mmol} / \mathrm{mol}$ [5.5\%]) (Fig. 1). Glibenclamide (dose at the time of hospitalisation: $0.08 \mathrm{mg} \mathrm{kg}^{-1} \mathrm{day}^{-1}$ ) was stopped and insulin therapy was commenced according to the Glucose Evaluation Trial for Remission (GETREM) protocol $\left(0.05 \mathrm{U} \mathrm{kg}^{-1}\right.$ day $^{-1}$ 


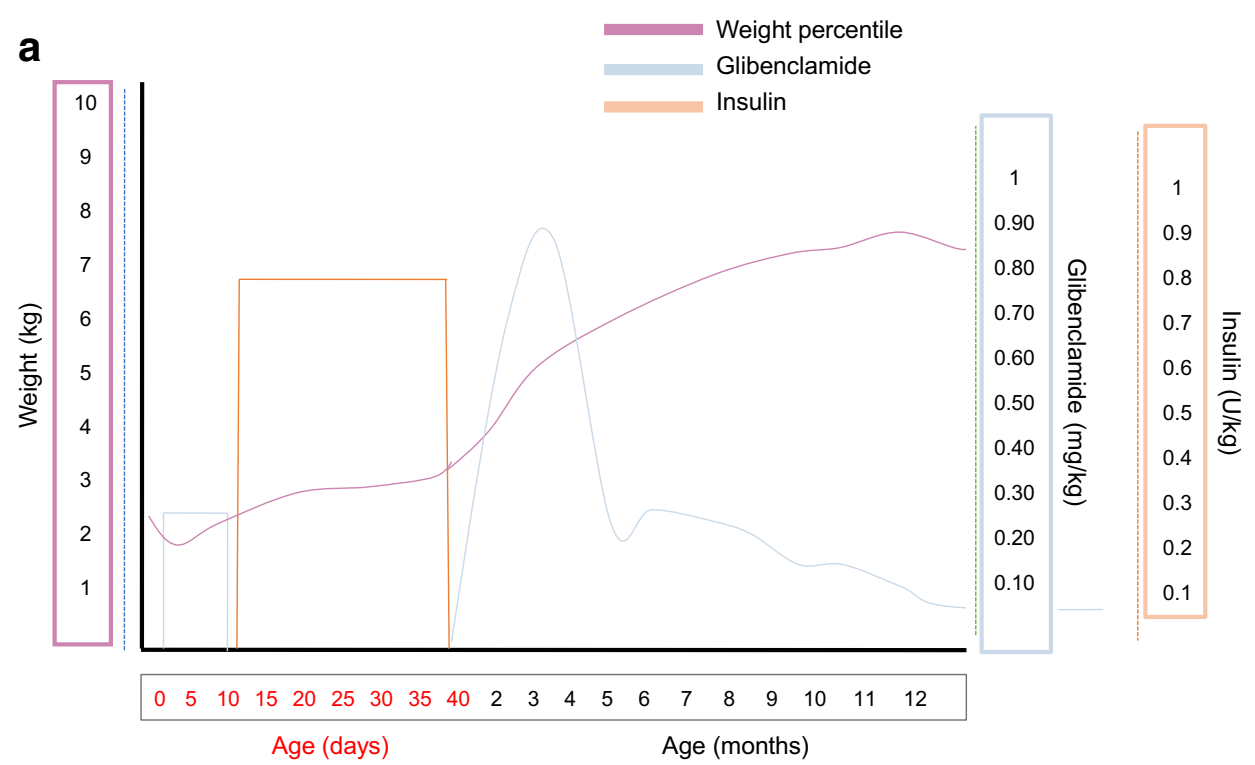

b

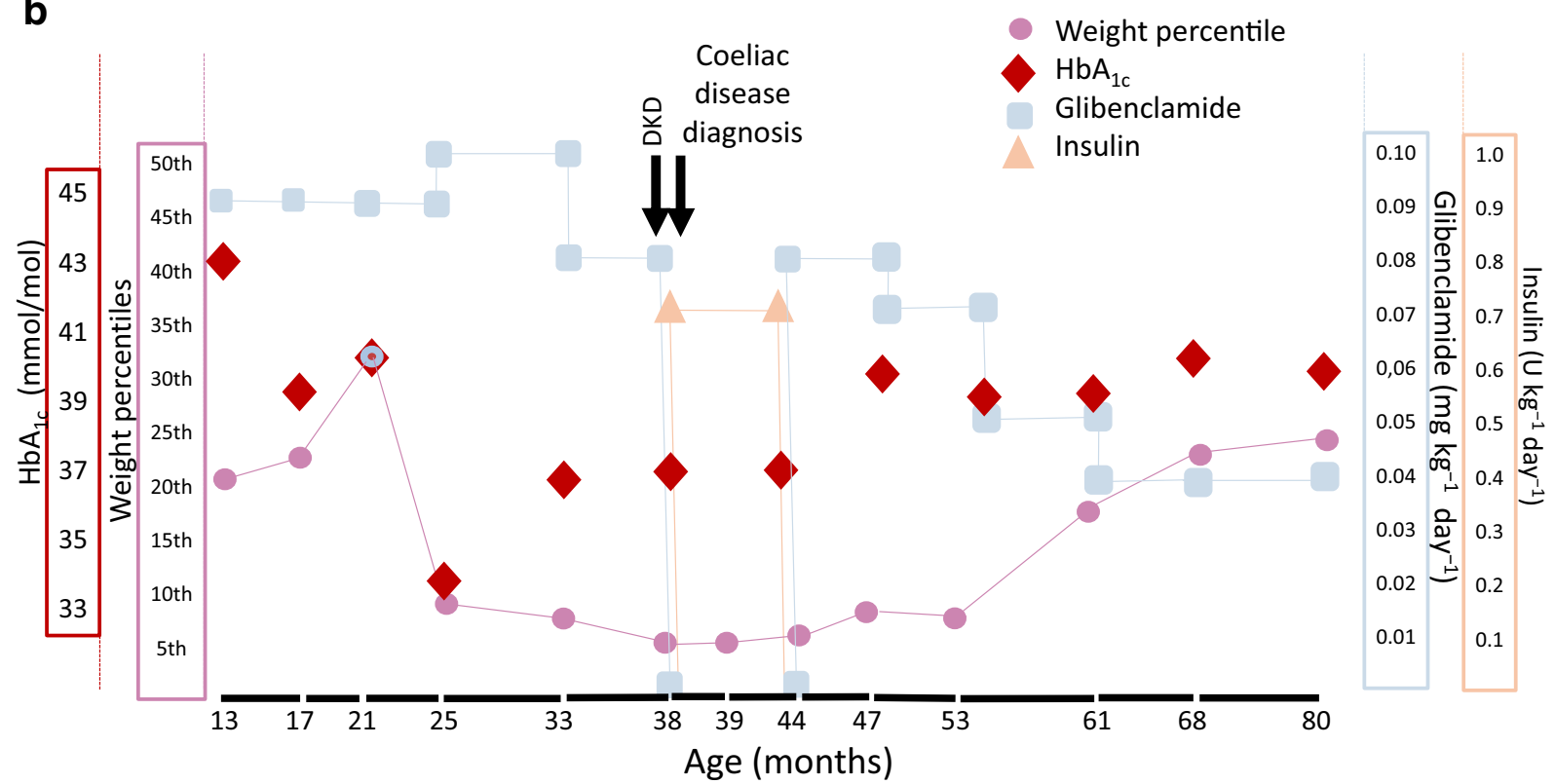

Fig. 1 (a) Clinical course during the first year of life. (b) Clinical course after the first year of life. Effect of glibenclamide in the patient before the diagnosis of coeliac disease, at the time of the DKA episode and after the coeliac disease diagnosis and introduction of gluten-free diet therapy

i.v.) [5]. The parents informed us that there had been no changes in the therapeutic regimen and so we sought the possible causes of metabolic derangement. Informed consent was given and our investigation was carried out in accordance with the Declaration of Helsinki as revised in 2008.

\section{Results}

Blood analysis showed an elevation in aminotransferases (aspartate aminotransferase [AST]: $58 \mathrm{U} / 1$, alanine aminotransferase [ALT]: $46 \mathrm{U} / \mathrm{l})$ and microcytic anaemia (mean corpuscular volume [MCV]: $65 \mathrm{fl}$, mean corpuscular haemoglobin $[\mathrm{MCH}]: 19 \mathrm{pg} / \mathrm{cell})$ with hyposideraemia $(0.15 \mu \mathrm{g} / \mathrm{ml})$. An abdomen ultrasound was normal. Further investigations revealed that the patient carried coeliac disease-predisposing HLA haplotypes (HLA DQ2 positive, DQ8 negative) and unequivocally elevated transglutaminase 2 (TG2) IgA (96 U/ml; positive $>16 \mathrm{U} / \mathrm{ml}$ ). Jejunal biopsy confirmed the diagnosis of coeliac disease. A gluten-free diet was prescribed to the patient with normalisation of aminotransferases, blood iron levels and erythrocyte analysis and a 
substantial decrease of TG2 IgA titre $(7.0 \mathrm{U} / \mathrm{ml}$ after 1 year; negative $<9 \mathrm{U} / \mathrm{ml}$ ), a sign of adherence to the gluten-free diet [6]. Six months from the start of the gluten-free diet, glibenclamide was re-introduced at the same dose (i.e. $0.08 \mathrm{mg} \mathrm{kg}^{-1}$ day $^{-1}$ ) that was administered at the time of hospitalisation (Fig. 1). Over a period of about 3 years glibenclamide was progressively tapered off to the current dose of $0.04 \mathrm{mg} \mathrm{kg}^{-1} \mathrm{day}^{-1}$. $\mathrm{HbA}_{1 \mathrm{c}}$ remained stable between 39 and $40 \mathrm{mmol} / \mathrm{mol}$ [5.8-5.9\%], slightly higher than the values observed immediately before and during insulin therapy for DKA (Fig. 1). At the diagnosis of coeliac disease we again investigated autoimmune diabetes markers (GAD, IA2, IAA and ZnT8 autoantibodies) which were negative, demonstrating the nonautoimmune pathogenesis of diabetes. For this reason, the coexistence of the two diseases in our patient has to be considered accidental.

\section{Discussion}

This case demonstrates how coeliac disease may hamper sulfonylurea therapy in patients with PNDM linked to $\mathrm{K}_{\mathrm{ATP}}$ mutations, and probably in other patients treated with this category of drugs. We previously described an individual diagnosed with neonatal diabetes caused by the KCNJ11/ R201H mutation, who was successfully switched to glibenclamide as a young adult [7]. The patient missed follow-up visits for 16 months, and asked for medical advice again when she experienced a worsening of her metabolic control ( $\mathrm{HbA}_{1 \mathrm{c}} 99 \mathrm{mmol} / \mathrm{mol}$ [11.2\%]) in parallel with a lack of compliance with her gluten-free diet, as evidenced by the raised TG2 IgA titre from 9.3 to $26.7 \mathrm{U} / \mathrm{ml}$ [8]. Of note, her TG2 antibody titre decreased (26.7 to $7.6 \mathrm{U} / \mathrm{ml})$, together with her $\mathrm{HbA}_{1 \mathrm{c}}(99 \mathrm{mmol} / \mathrm{mol}$ to $55 \mathrm{mmol} / \mathrm{mol}$ [11.2\% to $7.2 \%$ ]) and effective glibenclamide dose ( 0.40 to $0.34 \mathrm{mg} \mathrm{kg}^{-1}$ day $\left.^{-1}\right)$ after 6 months of strict gluten-free diet. Secondary failure of sulfonylureas seems to be linked to different causes, from unwise selection of patients or inadequate dosage of the drug [9] to lower age and beta cell function at the start of sulfonylurea therapy [10]. Our data support the notion that coeliac disease can be an additional - and rectifiable - cause of secondary failure. It is known that coeliac disease can impair absorption of levothyroxine, paracetamol (acetaminophen) and practolol [11] and a reduced absorption of glibenclamide was likely at work in our case, as suggested by the dynamics of hyposideraemic microcytic anaemia and metabolic control at the diagnosis of coeliac disease and after a gluten-free diet.

Another important aspect of this case is the patient's failure to thrive during the attempt to switch to glibenclamide. This patient is the only one, among the 30 patients with KCNJ11PNDM in the Italian dataset (F. Barbetti, unpublished results) who received glibenclamide as early as a few days after birth; this early treatment was partially because of the family history of paternal mutation and, in addition, the mild muscle hypotonia found in this infant that prompted us to perform this early attempt at sulfonylurea therapy, considering that the neurological defects observed in PNDM patients may benefit from early treatment with sulfonylureas. At any rate, these data seem to indicate that, in SGA infants with KCNJ11PNDM, sulfonylureas may prove insufficient to guarantee normal increase of body weight in the first month of life and that insulin therapy and delayed sulfonylurea treatment is desirable until proper body weight is achieved.

In conclusion, a sudden failure of sulfonylurea therapy in a patient who has previously responded well to this category of drugs warrants a search for coeliac disease.

Acknowledgements We gratefully acknowledge G. Diedenhofen for proofreading the paper.

Data availability All the data reported in this article are available on request from the authors.

Funding Open access funding provided by Università degli Studi della Campania Luigi Vanvitelli within the CRUI-CARE Agreement. This research received no specific grant from any funding agency in the public, commercial or not-for-profit sectors.

Authors' relationships and activities The authors declare that there are no relationships or activities that might bias, or be perceived to bias, their work.

Contribution statement All authors reviewed and provided feedback on manuscript drafts and approved the final version of the paper. In addition, authors had the following responsibilities: DI, AZ and FB conceived the original idea, wrote the manuscript and contributed to the discussion. ADN, AP, FC, MCR and GR collected and analysed data and contributed to the discussion. MA and SA analysed data and elaborated the figures. DI, AZ, ADN, SA, GR, MA and MCR followed up the patient. FB supervised the paper. DI is the guarantor of this paper.

Open Access This article is licensed under a Creative Commons Attribution 4.0 International License, which permits use, sharing, adaptation, distribution and reproduction in any medium or format, as long as you give appropriate credit to the original author(s) and the source, provide a link to the Creative Commons licence, and indicate if changes were made. The images or other third party material in this article are included in the article's Creative Commons licence, unless indicated otherwise in a credit line to the material. If material is not included in the article's Creative Commons licence and your intended use is not permitted by statutory regulation or exceeds the permitted use, you will need to obtain permission directly from the copyright holder. To view a copy of this licence, visit http://creativecommons.org/licenses/by/4.0/.

\section{References}

1. Tonini G, Bizzarri C, Bonfanti R et al (2006) Sulfonylurea treatment outweighs insulin therapy in short-term metabolic control of 
patients with permanent neonatal diabetes mellitus due to activating mutations of KCNJ11 (Kir6.2) gene. Diabetologia 49:2210-2213

2. Babenko AP, Polak M, Cavé H et al (2006) Activating mutations in the $A B C C 8$ gene in neonatal diabetes mellitus. N Engl J Med 355: 456-466

3. Bowman P, Sulen A, Barbetti F et al (2018) Effectiveness and safety of long-term treatment with sulfonylureas in patients with neonatal diabetes due to $K C N J 11$ mutations: an international cohort study. Lancet Diabetes Endocrinol 6:637-646

4. Masia R, Koster JC, Tumini S et al (2007) An ATP-binding mutation $(\mathrm{G} 334 \mathrm{D})$ in $K C N J 11$ is associated with a sulfonylureainsensitive form of developmental delay, epilepsy and neonatal diabetes. Diabetes 56:328-336

5. Pozzilli P, Manfrini S, Buzzetti R, MDIAB Group et al (2005) Glucose evaluation trial for remission (GETREM) in type 1 diabetes: a European multicentre study. Diabetes Res Clin Pract 68(3): 258-264

6. Hindryckx P, Levesque BG, Holvoet T et al (2018) Disease activity indices in coeliac disease: systematic review and recommendations for clinical trials. Gut 67:61-69
7. Colombo C, Delvecchio M, Zecchino C et al (2005) Transient neonatal diabetes is associated with a recurrent $(\mathrm{R} 201 \mathrm{H})$ KCNJ11 (KIR6.2) mutation. Diabetologia 48:2439-2441

8. Delvecchio M, Zecchino C, Faienza MF et al (2009) Sulfonylurea treatment in a girl with neonatal diabetes (KCNJ11 R201H) and celiac disease: impact of low compliance to the gluten free diet. Diabetes Res Clin Pract 84:332-334

9. Camerini-Davalos RA, Marble A (1962) Incidence and causes of secondary failure in treatment with tolbutamide. JAMA 181:89-92

10. Matthews DR, Cull CA, Stratton IM, Holman RR, Turner RC (1998) UKPDS 26: sulfonylurea failure in non-insulin-dependent diabetic patients over six years. Diabet Med 15:297-303

11. Tran TH, Smith C, Mangione RA (2013) Drug absorption in celiac disease. Am J Health-Syst Pharm 70:2199-2206

Publisher's note Springer Nature remains neutral with regard to jurisdictional claims in published maps and institutional affiliations. 